\title{
Um país de maravilhas! O infantil da utopia ${ }^{1}$
}

\section{A country of wonders! The infantile of utopia}

Marcos Pippi de Medeiros*2

Edson Luiz André de Sousa*3

Neste ensaio procuramos construir alguns laços entre o infantil na concepção psicanalítica e o universo das utopias. A partir da versão cinematográfica de Alice no país das maravilhas de Jam Švankmajer - em que o autor consegue nos oferecer uma perspectiva do universo carroliano de Alice, aproximado do sonho e do brincar das crianças na concepção freudiana - procuramos aproximar o infantil e a utopia, relacionando o "País das maravilhas" apresentado por Švankmajer, da ilha Utopia, de Morus, no sentido de demonstrar como o infantil permite o acesso às construções utópicas a partir de um corte ou furo nas palavras-imagens do infantil, como exigência de criação, pelo brincar, de um litoral que nos dá acesso a ilhas, territórios que resistem à literalidade das formas instituídas da realidade, como utopia.

Palavras-chave: Infantil, utopia, psicanálise, escrita, brincar

*1 O presente artigo é parte da tese de doutorado em Psicologia Social e Institucional da Universidade Federal do Rio Grande do Sul - UFRGS, realizado junto ao LAPPAP - Laboratório de Pesquisa em Psicanálise, Arte e Política, intitulado Poéticas do Infantil: três ensaios de psicanálise e utopia, sob orientação do prof. dr. Edson Luiz André de Sousa e subvencionado com bolsa de pesquisa CAPES.

*2 Universidade Franciscana - UFN (Santa Maria, RS, Brasil).

*3 Universidade Federal do Rio Grande do Sul - UFRGS (Porto Alegre, RS, Brasil). 


\section{Rumo a um país de maravilhas!}

Alice no país das maravilhas parece um livro que nasceu procurando uma linguagem para além das palavras. Pelo menos é isto que Alice, no livro, desapontada com o livro de sua irmã, de início, nos insinua: "e de que serve um livro (...) sem desenhos ou diálogos?" (Carroll, 1998, p. 11). Talvez não seja por mero acaso que Alice tenha sido das primeiras obras filmadas no cinema, uma produção britânica de 1903 feita por Cecil M. Hepworth e PercyStow; e embora nos pareça hoje um teatrinho de escola em preto e branco, quase um suporte de imagens mudas, em movimento, para o texto de Alice, já contava com pretensiosos efeitos especiais a dar mostras do futuro do longo affair de Alice com o cinema e as suas tecnologias, tantas vezes filmada em diversas versões.

A obra de Lewis Carroll — pseudônimo do professor de matemática Lutwidge Dodgson - constrói imagens de sonho, joga "primitivamente" com as palavras. Um brincar infantil, muitas vezes difícil de reconhecer no contemporâneo, e que acabou por compor uma escola literária britânica chamada de non sense.

Se o texto de Alice nasce pedindo por imagens, suspeitamos, contudo, que essas imagens precisam brotar desse mesmo universo de sonho, tal qual as imagens claudicantes de um brincar infantil ou de um sonho. Imagens em movimento, pondo em cena esse objeto evanescente, misto de perda e excesso, a constituir uma aventura utópica da criança que, perdida dos mapas e lógicas de um mundo adulto — simplesmente lhe escapam —, afirma seu jogo de non sense no qual constrói sua utopia.

Nesse sentido, é da "maravilhosa" produção cinematográfica de Alice, de Jam Švankmajer que quero me aproximar, sobretudo, por essa intertextualidade tão sensivelmente afinada com o texto de Carroll. Trata-se de uma versão que parece estabelecer um jogo 


\section{LITERATURA, ARTE, CULTURA}

com as imagens, captando o fundamental da obra original, no sentido de nos aproximar desse universo de angústia e sonho, de um "estranhamento familiar" e, principalmente, de um universo que vem a atualizar o texto de Alice como um texto utópico.

O diretor tcheco, cuja obra como um todo traz a presença desse universo "carolliano" em suas produções, se utiliza do stop motion como recurso fílmico, como tecnologia para seus "efeitos especiais" e, em geral, em suas montagens cinematográficas. Esta "antiga" técnica de cinema trata de produzir o movimento a partir de sucessivos registros fotográficos de objetos inanimados em diferentes posições. Em Alice, de 1988, esse recurso é utilizado não apenas como uma forma interessante de resolver muitos desafios do texto à filmagem, mas também de imprimir uma estética mais artesanal, contrastando com a "imaterialidade" das tecnologias em 3D, por exemplo. Os diversos objetos, brinquedos se animam, se fazem metáforas onde o brincar infantil ganha vida dos próprios objetos da infância, na mesma medida em que os mesmos ganham vida na tela. Essas duas obras que parecem constituir um duplo - para além das muitas versões de Alice no cinema - aproximam-se de uma utopia em um sentido diverso do furor realizante das utopias tradicionais, introduzindo uma "função do irreal" que vai também aproximar nossa argumentação daquilo que no campo psicanalítico constituiu, desde Freud, uma utopia.

Alice, de Švankmajer, é uma utopia que se redobra do texto de Carroll. Resguarda esse infantil como resistência do desejo em um mundo carente de sonho, que traz em sua invenção do inconsciente uma aproximação como isso que resiste criativamente em nós ante os mecanismos anestésicos da experiência, pondo um risco de ocaso ao sujeito no contemporâneo. E, principalmente, joga com esses objetos que se põem como perda, como resto, demasiados reais e impossíveis; como um fazer com os restos (diurnos) de um sonho que pedem narrativa, nos aproximando de uma função poética da utopia onde o infantil da experiência psicanalítica insiste.

Zarpemos, então, nessa nau, partindo do interior de um continente em busca, também, de nossa ilha utópica, de um país de maravilhas. Nessa nau de escritura - que nos tira os pés do chão por certo tempo e permite uma travessia que faz furo nesse território estagnado de fronteiras e mapas, de fronteiras fixas, delimitando sentidos -, abre-se um imenso litoral. "O comandante Utopos fez-me uma ilha, eu que não era ilha" (Morus, 2009, p. 224). Era interior, um continente ligado por um istmo, seguia por uma estrada que delimitava fronteiras, interiores e exteriores. O que, por hora, 
era uma "fantasia extravagante" (Abraxa), aberto o canal, se faz uma ilha de forma tal, que a ilha foi cercada pelas águas do mar.

Assim como a ilha de Utopia, de Morus, uma ilha estruturada como uma linguagem; letra e significante, assim é esse país de maravilhas. Mas para acessá-lo é preciso situar, para além desse corte, o furo no real que constitui sua topologia. Mais ainda, uma imagem-valise se projeta do corte ao furo. Um ravinamento que faz furo, buraco; um litoral, então, dá acesso a esse (utópico) país de maravilhas.

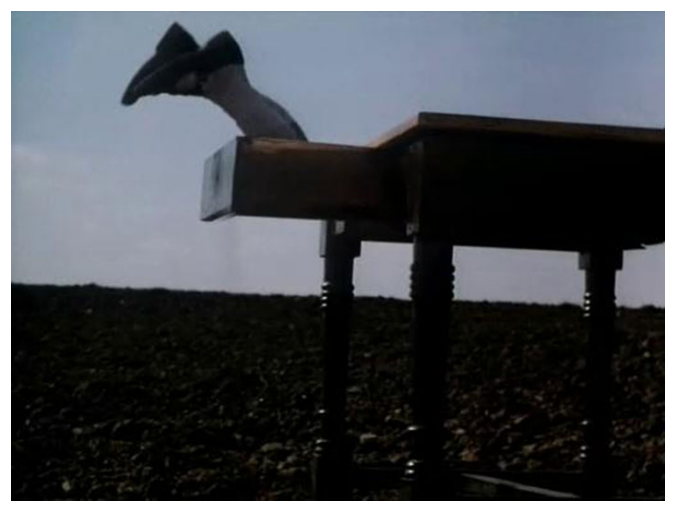

Figura 1

Por esse "furo no real", Alice transpõe-se para esse universo de sonho, esse U-tópos (não-lugar) que só se pode acessar como ato de escritura em seu trabalho de ravinamento. "Litura, lituraterra, rasura de traço algum que seja anterior é isso que do litoral faz terra. Litura pura é o literal. Produzir essa rasura é reproduzir a metade com que o sujeito subsiste" (Lacan, 1971/2003, p. 21). O que Lacan (1971/2003), em "Lituraterra", nos apresenta, é a letra, vestígio real do gozo da escrita, que ele bem chama de ravinamento das águas, termo que evoca o gozo de romper um semblante. A escrita é esse ravinamento. $\mathrm{O}$ corte a desdobrar infinitamente o oito interior; um corte "moebiano".

Aí, justamente nesse corte, cai Alice e, atravessando esse litoral de matéria de sonho, acessa esse país non sense, estruturado como o brincar das crianças. Essa topologia do sonho que nos olha em toda superfície, como nos fala Didi-Huberman (2010), para além do visível que constitui sua evidência:

Seguindo uma mudança, de uma escala digna de Lewis Carroll —, a própria superfície se torce de rir, e é desse modo que ele indica às suas pequenas órfãs 


\section{LITERATURA, ARTE, CULTURA}

a vocação essencial de toda a superfície que nos olha, isto é, de toda superfície que nos concerne para além de sua visibilidade evidente, sua opticidade ideal e sem ameaça. Quando se torna capaz de abrir a cisão do que nos olha no que vemos, a superfície visual vira um pano, um pano de vestido ou então a parede de um quarto que se fecha sobre nós, nos cerca, nos toca, nos devora. Talvez só haja imagem a pensar radicalmente para além do princípio de superfície. (p. 87)

Uma superfície que se torce e deixa aparecer imagens que nos olham, fazendo furo no olhar. Uma concepção de utopia da qual tentamos nos aproximar entre Carroll e Švankmajer.

Neste sentido, ainda no intuito de, por um lado, defender o texto de Lewis Carroll como um texto utópico, assim como a versão de Švankmajer e, ao mesmo tempo, poder situar de que utopia se trata, talvez seja oportuno introduzir as concepções de Roger Dadoun (2015) acerca da utopia. Ele vai aproximá-la daquilo que nomeia como uma emocionante racionalidade do inconsciente.

Poderíamos nos contentar de ver, no uso comum e generalizado do termo "utopia", uma simples inércia da linguagem, um estereótipo característico de um discurso profano e superficial - e como o eco, banalizado, de um uso polêmico e ideológico nutrido disto que poderíamos nomear, indiferentemente, empirismo, realismo ou positivismo. Mas a persistência do rumor desvalorizador e sua resistência aos esclarecimentos históricos como aos exigentes esforços de racionalidade convidam a buscar uma origem ou uma função mais singulares, mais insólitas, da utopia — e a buscá-las, não há outra escolha possível, do lado do inconsciente. (s/p.)

Nesse sentido, o autor nos aproxima de um inconsciente da utopia, o qual vai opor a concepção de espírito da utopia. Ao fazê-lo nos leva em seu argumento para um sentido outro, ao da vocação realista da utopia, ou seja, idealmente orientada para uma realização. Essa orientação é circunscrita por um tempo geométrico, cuja seta aponta para um futuro organizado por uma racionalidade ideal sublimadora. De outra forma, a essa concepção tradicional, Dadoun vai apontar para uma utopia regida pela racionalidade emocionante do inconsciente, que não parte do vetor tradicional ordenado no sentido de um presente em direção ao futuro, mas de um umbigo do tempo, rumo a um presente do qual aproxima uma perspectiva psicanalítica da utopia.

Dadoun (2015) deixa por um instante em suspenso a discussão acerca dessas duas concepções antagônicas da utopia para analisar as linhas de forças que a constituem. Vai situar, nesse sentido, que uma utopia é um esforço de pelo menos três linhas de desenvolvimento compreendidas como: 
racionalização, organização e escritura, compondo um tríptico a partir do qual se apresenta o "manifesto" do trabalho de uma utopia; elementos que, aliás, encontramos no texto de Lewis Carroll, assim como em Utopia, de Morus, citada pelo autor. Embora possamos reconhecê-lo no texto de Carroll, nos resta perguntar: de qual trabalho da razão se trata? Dadoun (2015) vai, dessa forma, argumentar enfaticamente sobre a pressão que o trabalho utópico vai sofrer no sentido de uma realização por um "princípio de realidade" que tenta, sobre ele, exercer sua lei:

digamos pois, por brincadeira - uma brincadeira de consequências temíveis - que este "em direção a" que força a utopia a copular no leito do real, é o "verme", o parasita alojado no fruto da utopia e que o rói, é o agente da sua decomposição, de sua putrefação. A história traz sobre este ponto ilustrações exemplares, esmagadoras, sob a forma, precisamente, de um teste de realidade: todas as vezes que a utopia é forçada a entrar nos fatos, de passar ao ato, de se deitar no leito do real, não se obtém nada além de obscenidade, podridão e desastre. É preciso concluir disso que a vocação da utopia não é de ir "em direção à" realidade, mas exatamente ao contrário: utopia versus realidade utopia contra o real. (s/p.)

Neste movimento, o autor, em uma volta, nos permite pensar a utopia como uma formação do inconsciente associada, justamente, ao trabalho do sonho, "de maneira que tanto na volta da utopia é o inconsciente mesmo que se expõe e se afirma" (Dadoun, 2015, s/p.). Assim, um desejo de utopia se impõe como um desejo de produzir uma superação das dicotomias, dos "esquizos" da realidade e do sonho, do individual e do social etc.

$\mathrm{Na}$ utopia, racionalidade, sociabilidade e linguagem mantém uma rica ligação umbilical com sua fonte inconsciente; sua vocação, sua finalidade, sua razão de ser consiste precisamente em fazer funcionar tal ligação, a desenrolar todas as suas virtualidades - e não de desviar dela ou de rompê-la para responder — de maneira errada! - às solicitações vorazes do real. Visto que, justamente, para a utopia, é nesta fonte inconsciente que reside a força principal de resistência à realidade - o que nos leva a reconhecer a utopia, através de uma simetria com a "função do real", cara à psiquiatria normativa, uma função do irreal. (Dadoun, 2015, s/p.)

Esse País de Maravilhas, em um vetor distinto da Ilha de Utopia de Morus, também nos leva para uma concepção da utopia como resistência à realidade, uma vez que vai nos situar nesse litoral aberto para além dos limites do dizível, no brincar da criança, exigindo uma linguagem própria, propriamente poética, descompromissada com a realidade do sentido, que 


\section{LITERATURA, ARTE, CULTURA}

fracassa em compreender, que se tece em torno de um objeto (perdido) que tenta a todo instante recuperar, sempre fracassando, sempre repetindo seu cortejo de imagens claudicantes.

Louis Marin (1989) nos fala da utopia, em primeiro lugar, dizendo que ela é simplesmente um nome que Thomas Morus inventa. Ela é um nomelugar, uma nomeação inscrita com a marca própria da linguagem. Morus, portanto, nos conduz à ficção, quando nos leva a sua Ilha de Utopia:

O nome da ilha em seu lugar de dito, não de inexistência ou de irrealidade, mas do indefinido: ou-topia; não-lugar. A ilha perfeita é, a dizer, um não-lugar. Ela pertence ao conjunto indefinido, sem limite categorial ou semântico, de tudo o que não está localizado no espaço geográfico, cartográfico, político ou ético [...]. (p. 14; tradução nossa)

A utopia é animada por seus contornos, de textos e imagens, cujo brincar poético, "serio ludere", inverte as palavras, dando a elas seu contrário lógico, como vemos também, como exemplo, em Anidro (o rio sem água), onde também podemos vislumbrar sua designação irônica:

(...) o inventor de Utopia tenta dar a sua prática mesma, de linguagem e suas formas literárias, histórias, descrições, discursos, que dão à sua produção, o estatuto de ficção poética. Ele nem afirma que seu discurso tem uma referência real, nem afirma que não - estaria mentindo. É o verbo, ele mesmo, como poiesis, como prática criativa que ao manter em suspenso a questão da referência entre irrealidade e realidade, imaginário e existente, se instaura na realidade e pela existência do poema. (p. 14; tradução nossa)

Isso também nos diz o quanto Alice, pela escrita de Carroll, é um texto utópico, como uma experiência nos limites do dizível, qual um Joyce ou Beckett, o que exige uma linguagem muito particular, poética, para poder se dizer. Uma linguagem que vai apontar para certo "fracasso da compreensão" no intuito de dizer o inominável infantil? Língua que nos ajuda a recuperar certo objeto, como nos diz Lacan (2004) em sua Homenagem a Lewis Carroll. "Não há travessia possível, anuncia Beckett, sem este imperativo de ter que abrir a boca para tentar desenhar um litoral de linguagem que arme uma geografia mínima que nos situe no mundo" (Sousa, 2014, p. 268).

Ao retomar com Lacan em seu "Lituraterra", que a literatura é uma acomodação de restos, Sousa (2014) vai apontar para esse necessário "colapso do entendimento" a partir de onde a literatura abre seus buracos que permitem a constituição do desejo. Um verdadeiro arejamento da linguagem naquilo que constitui o fundamental da função poética, para não 
dizer, utópica. Assim, essa geografia dos abismos no texto de Carroll, a todo custo, com risco, desenha um repetido e inesgotável fazer com os restos desse infantil nunca plenamente nominável — metonímico tal qual o brincar das crianças — , cujo objeto está de saída, faltante, e cujas imagens, sempre em fracasso, desenham novos relevos esburacando a superfície dos lugares desertos de sonho.

Como enfrentar esse desafio do limite do dizer? Como encontrar um nome para aquilo que não tem um nome (inominável)? Ou seja, como se confrontar com essa insuficiência da linguagem e, ao mesmo tempo, o poder da linguagem na sua insuficiência? (Sousa, 2014, p. 270)

Acerca desse objeto que a escrita, ao menos em parte, recupera no limite do dizer, derivam ao menos três associações imediatas (no sentido desse objeto que a escrita tenta recuperar), que revelam seu caráter utópico: a primeira nos é apresentada por Didi-Huberman em seu "Jogo do esvaziamento"; isso na medida em que ele vai considerar essa posição singular da criança deixada a sós nesse estupor da espera, à espreita, nesse fundo de ausência (materna) de onde advêm as imagens.

Até o momento em que ela o vê de repente se abrirá, atingido por algo que, no fundo - ou do fundo, isto é, desse mesmo fundo de ausência —, racha a criança ao meio e a olha. Algo, enfim, com o qual ela irá fazer uma imagem. A mais simples imagem, por certo: puro ataque, pura ferida visual. Pura moção ou deslocamento imaginário. Mas também um objeto concreto - carretel ou boneca, cubo ou lençol da cama - exatamente exposto a seu olhar, exatamente transformado. Um objeto agido, em todo caso, ritmicamente agido. (Didi-Huberman, 2010, p. 79)

Desse objeto do Fort-Da, pelo jogo incessante da criança metaforizando ausências por um fio, por esse "objeto agido" pelo jogo de presença e ausência da criança; recuperação metonímica de um objeto perdido decorre outra, a do objeto (a) de Lacan. Este último, que vai ser aproximado à constituição da utopia por Sousa (1990) em "A imagem perfeita":

Uma porta que se abre neste ponto é a de pensar o objeto $a$ como utopia. Objeto $a$ como causa, em posição evanescente, mas que nos coloca na via de uma ética do desejo, convocando o sujeito a novas posições, novos cortes de estilete, enfim, tentar produzir e construir um estilo. Em que sentido podemos pensar, neste ponto, em utopia? No sentido em que diz Fredric Jameson, que a vocação de toda a utopia é o fracasso. (Sousa, 1990, p. 16) 


\section{LITERATURA, ARTE, CULTURA}

Por fim, uma última imagem desse objeto (a) da utopia nos oferece Sarduy (1979), em seu ensaio "Por uma ética do desperdício. Ao falar do erotismo, acaba por desenhar o espaço do Barroco como espaço de superabundância, e também de desperdício. Essa "Ética do desperdício" da qual nos fala vem interrogar, justamente, uma "lógica do valor", sobretudo, do valor daquilo que, no desperdício barroco, se apresenta como resto. Ética que vai afirmar o valor do resto como tal. Assim, postula que a linguagem barroca vai tentar se aproximar de um objeto que seja, em sua demasia ou na perda, um objeto parcial, no sentido oferecido pela psicanálise desde Freud. Objeto que é, sobretudo, o suporte simbólico do espaço Barroco; objetos do infantil: fezes, voz, olhar etc., como também, ouro, matéria constituinte. "Resíduo que poderíamos descrever como a (a)lteridade, para marcar no conceito a contribuição de Lacan, que chama a esse objeto precisamente (a)" (Sarduy, 1979, p. 77). Um objeto descrito não apenas como resíduo, mas também como queda ou perda, como a constatação de um fracasso:

o que significa a presença de um objeto não representável, que obsta franquear a linha da Alteridade (A): correlação biunívoca de (a), (a)lice que irrita Alice porque a última não consegue fazê-la passar para o outro lado do espelho.

A constatação do fracasso não implica a modificação do projeto, mas ao contrário, a repetição do suplemento; esta repetição obsessiva de uma coisa inútil (já que não tem acesso à entidade real da obra) é o que determina o barroco enquanto jogo, em oposição à determinação da obra clássica enquanto trabalho. (Sarduy, 1979, p. 77)

Através desse jogo, que também constitui o Barroco, dessa repetição do "inútil", comum ao próprio espaço do brincar para as crianças, Alice, entre o excesso e a perda, nos leva para esse mais além do espelho de onde brotam as palavras e os sonhos.

Imagine agora esse país de maravilhas! Não é difícil, um país que teve uma origem de existência, como obra, na aurora da ciência. Sua publicação se deu no mesmo ano em que Darwin publicava $A$ origem das espécies, texto que também indaga uma origem. Se o primeiro encontra essa origem biológica que fundamenta uma evolução, o texto de Carroll nasce indagando, quiçá reivindicando outra origem do humano, qual um duplo onírico, sintomático. Na produção de Švankmajer, não faltam referências, espalhadas, vivas, como os restos diurnos de que os sonhos são feitos: tanto dos compassos e réguas do mítico professor de matemática, como muitas evocações de $A$ origem das espécies, pelos vidros e esqueletos de um laboratório onírico de biologia, que já se mostram pelas frestas de um elevador por aonde, lentamente, Alice 
vai caindo, enquanto, curiosa, olha e manuseia as inúmeras prateleiras; como também, pelos animais fantásticos feitos destes mesmos restos, que se condensam e se deslocam por esse mundo de sonho, pelas potentes imagens claudicantes que brotam a todo o momento.

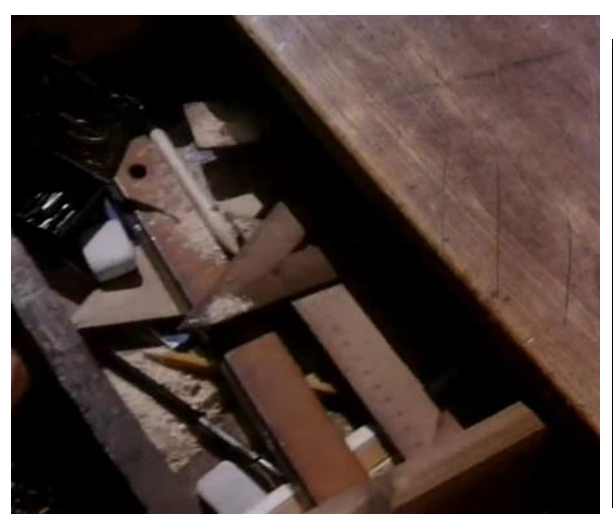

Figura 2

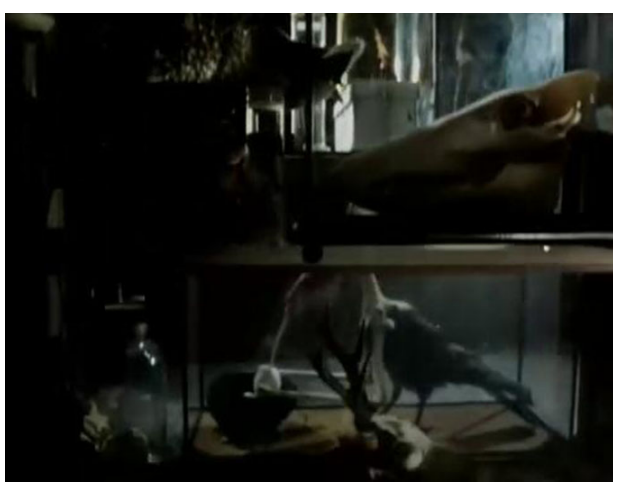

Figura 3

Uma origem na linguagem, emergindo de um universo de sonho que evoca uma utopia infantil, à qual a psicanálise tem feito testemunho. $\mathrm{O}$ maravilhoso país onde se travam as construções mais fecundas do infantil; as experiências de "estica e encolhe" os contornos do corpo, a invenção das charadas sem resposta (verdadeiras questões lançadas ao previsível sujeito da ciência). Assim se apresenta esse grande ensaio épico das ciências, desenhando uma utopia como furo, mas, também, como resistência da imaginação.

Jacoby (2007) discute o recurso da imaginação como aquilo que vem, justamente, nutrir a utopia. Doravante, compreende que a imaginação passa a ser um "verme" que a ciência tentará superar, cauterizar como último obstáculo no caminho da felicidade. Mas, ao constatar que a subversão tão ameaçadora da imaginação é justamente o que sustenta o pensamento utópico, se pergunta: afinal, e o que sustenta a imaginação? De qualquer forma, "se a infância desestruturada sustenta o pensamento utópico, então o esvaecimento do primeiro implica o enfraquecimento do último - o pensamento utópico" (Jacoby, 2007, p. 64). Em meio a tantas incertezas, o que Jacoby sustenta é o risco, a probabilidade de que uma colonização do espaço e do tempo infantil ponha em xeque uma "imaginação independente", tornando-a com menos recursos e inclinações para o sonho utópico. 


\section{LITERATURA, ARTE, CULTURA}

Esse saber construído no inacabamento, na insuficiência, que põe a cena do infantil no campo de uma utopia, muitas vezes eclipsada pela alucinante velocidade industrial, obturada pela verdade de uma ciência sem sonho ou desejo, que se mira como em um espelho. "No jogo, a criança reinventa o mundo, cria suas próprias regras, brinca com a linguagem, muitas vezes construindo associações inusitadas e achando sentidos inesperados." (Sousa \& Endo, 2009, p. 65). Na obra poética e/ou artística encontra-se um infantil vivo e potente, ainda que "esquecido": "seu ato de criação desenha outro mundo possível. O que nos leva a pensar, seguindo a lógica freudiana, que todo ato de criação é, em última instância, um ato utópico. Utopia que abre novas imagens de mundo questionando a paralisia das imagens estagnadas" (p. 66). O poeta, por sua vez, faz equivaler seu ato criativo ao brincar infantil, como uma exceção em um mundo adulto em que já não se brinca.

Proposição que vai ao encontro de uma concepção de utopia, tal como nos aponta Sousa (2011):

(...) a utopia abre uma dimensão de reflexão crítica e introduz no espaço da vida uma zona de imaginação, de desequilíbrio, de suspensão. Podemos pensar a utopia como a introdução de um estrangeiro que nos permite lançar um olhar diferente para a paisagem que temos diante dos olhos. A utopia vem, portanto. se opor à tendência a repetição. Ela vem romper com a paixão da analogia, ao propor um não lugar. (p. 2)

A contundente atualidade de Alice reside justamente nessa tensão entre uma lógica racional que emerge com toda a força no século XIX e seu inconsciente. Neste sentido, sentencia Lacan (2004), Alice "é o épico da era científica". O texto de Lewis Carroll nos apresenta "verdades sólidas, embora não evidentes. Ali discernimos que, sem nos servir de qualquer distúrbio, podemos produzir o mal-estar, mas que desse mal-estar decorre um júbilo singular" (p. 7).

Um mal-estar que, a partir de Agamben (2005), podemos pensar como aquilo que vai estar no cerne da experiência do inconsciente, crise da qual a psicanálise vem a fazer sintoma. "Pois certamente na ideia de inconsciente, a crise do conceito moderno de experiência — ou seja, da experiência que se funda sobre o sujeito cartesiano - chega à sua evidência máxima" (p. 51). Ou então, como nos diz Luciano Elia (2010), "o sujeito é suposto pela ciência para, no mesmo ato, ser dela excluído, ou, mais exatamente, ser excluído do campo de operação da ciência" (p. 14). Assim, postula Agamben (2005) onde vigora uma lei científica, não se pode contar uma "estória". O projeto da ciência moderna ao colocar sob suspeita a imaginação como forma legítima 
da experiência, vai bani-la também como forma válida de conhecimento: do sujeito da experiência ao sujeito da alienação mental. A experiência psicanalítica, segundo Agamben (2005), está atravessada por essa crise vivida com mal-estar, uma vez que se trata justamente de uma experiência voltada ao Isso, ao Es freudiano e, nesse sentido, vai conceber esta experiência (a do inconsciente) qual um retorno, um "retrocesso", propriamente, à infância.

Algo que podemos também encontrar uma boa expressão naquilo que Freud (1905/1976a) vai formular em "Os chistes e sua relação com o inconsciente", acerca do infantil ligado à formação do dito espirituoso:

Pois o infantil é a fonte do inconsciente e os processos de pensamento inconscientes são exatamente aqueles produzidos na tenra infância. $\mathrm{O}$ pensamento que, com a intenção de construir um chiste, mergulha no inconsciente está meramente procurando lá a antiga pátria de seu primitivo jogo com as palavras. O pensamento retroage por um momento ao estágio da infância de modo a entrar na posse, uma vez mais, da fonte infantil de prazer. (p. 194)

O infantil, como um "conceito" produzido no campo da psicanálise, nasce com Freud. Embora o autor não tenha desenvolvido uma articulação mais elaborada e central do infantil em sua teoria, esse conceito é introduzido na obra freudiana para compor um campo que ultrapassa uma identificação com o universo da criança, como também, distinto e mesclado à noção de infância. Ele aparece em termos importantes como: sexualidade infantil, teoria sexual infantil, ou mais além, em termos como neurose infantil, apontando para sua atualidade como uma instância ligada aos processos clínicos. E também como lugar de uma experiência "perdida" da qual, contemporaneamente, podemos aproximar do fazer poético, a criação enquanto brincar, evocando um campo de jogo com o non sense, onde a arte emerge como um fazer com os restos da experiência muda do infans.

Para Zavaroni (2007) o infantil não possui uma organização mais central como conceito em meio às construções freudianas. Ao percorrer muitos dos textos em que o infantil aparece como questão na obra de Freud, a autora vai pontuando suas diversas expressões. Sobretudo como constitutivo do psiquismo humano a partir do desamparo infantil, como fantasia cujo estatuto adquire valor de verdade, psíquica, como também o conjunto das sensações gravadas, marcas mnemônicas, entre outros, encontrando sua construção mais aproximada como conceito, ao aparecer sob a expressão "fator infantil" na análise por Freud do "Homem dos lobos".

[...] em suas diferentes facetas, o infantil refere-se àquilo que, sob a ação do recalque, origina e "determina" o psiquismo humano. Referido há um tempo 


\section{LITERATURA, ARTE, CULTURA}

originário, o infantil inscreve-se no psiquismo humano como uma construção atravessada pela fantasia. No trabalho de psicanálise, o infantil comparece em um constante movimento de retorno e atualização daquilo que, no percurso do desenvolvimento pulsional, pode ser construído, somente a posteriori, como sendo a infância de cada analisando. (p. 69)

Esse infantil que nos faz novamente apostar nesse potente enlaçamento da produção de Švankmajer com o texto de Carroll. A construção desse país utópico, estruturado como um sonho, uma utopia instituída pelo avesso dos saberes e da lógica racional, ou mesmo, do destino biológico, demasiado real; animais extintos, corpo que espicha e encolhe. Rastros sem sentido. Denúncia de um tempo que urge sem que nunca se saiba. Afinal, para onde? Para quê? Caminhos traçados no sem sentido de uma lógica carregada de alteridade, mas também dos sentidos arbitrários do Outro. O Coelho Branco, emblema da antecipação e da prematuração da criança ante o tempo do Outro, também das demandas de uma temporalidade vertiginosa em nossos tempos, se anima, pelas "tintas" de Švankmajer, remetendo ao tempo que gasta, estraga os objetos. Corso \& Corso (2011) vão nos apontar para o quanto o devaneio de Alice em uma tarde de verão, nos permite - utopicamente - a visão de quão absurdo pode ser o mundo, quando paramos para olhar.

Como o coelho branco, corremos atrás de futilidades; distraímo-nos com rituais circulares como o Chapeleiro. [...] Reis, Rainhas e tribunais revelam toda a sua inconsistência e se estatelam, literalmente, como um castelo de cartas, sob os olhos da menina. (p. 280)

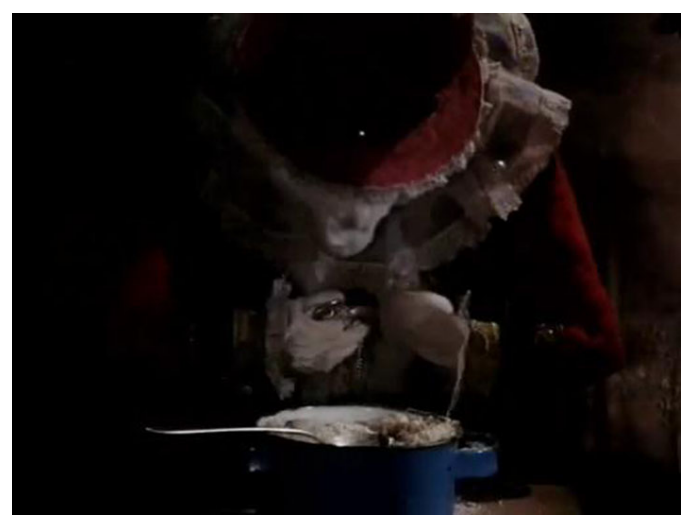

Figura 4 
Bela e melancólica imagem do Coelho que tira das entranhas, por um rasgo no tecido de sua feitura por onde a palha do forro escorre junto com o tempo, o relógio de bolso prateado, cuja antiguidade já anuncia: é tarde!

Alice, assim, é o épico científico, na medida em que se constrói com os restos mudos de uma experiência do infantil. Experiência essa, recalcada pelo saber dito científico, racional, indo ao encontro de uma subversão desse infantil, tão potente quanto utópico.

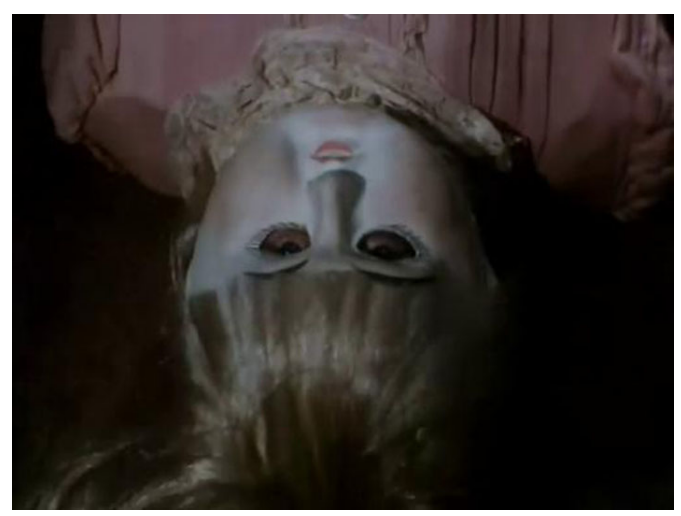

Figura 5

Uma forma de materializar a operação mesma da fantasia e do sonho se mostra, por exemplo, quando o diretor alterna a menina atriz, que faz o papel de Alice, com uma boneca (para as cenas mais arriscadas) que passa, então, a interagir com os diferentes personagens, objetos animados pelo desejo, todos dispostos qual o cenário de uma brincadeira de crianças:

Contudo, uma vez atingida a ideia de que podemos tornar um fator infantil como este responsável por sentimentos de estranheza, somos encorajados a verificar se podemos aplicá-la a outros exemplos do estranho. Na história do Homem de Areia, encontramos o outro tema destacado por Jentsch, de uma boneca que parece ter vida. Jentsch acredita que se cria uma condição particularmente favorável para despertar sentimentos de estranheza, quando existe uma incerteza intelectual quanto a um objeto ter ou não vida, e quando um objeto inanimado se torna excessivamente parecido com um objeto animado. Ora, certamente as bonecas são intimamente ligadas com a vida infantil. Lembremo-nos de que, nos primeiros folguedos, de modo algum as crianças distinguem nitidamente objetos vivos de objetos inanimados, e gostam particularmente de tratar as suas bonecas como pessoas vivas. (Freud, 1919/1976b, p. 291) 


\section{LITERATURA, ARTE, CULTURA}

Um efeito de estranhamento com que o diretor joga, a todo momento. $\mathrm{O}$ cenário sombrio e carcomido, a solidão silenciosa da aventura de Alice (vale ressaltar que o filme prescinde de trilha sonora), a atmosfera de sonho, dão à produção de Švankmajer um ar "angustiante", retorno de um encontro com um Unheimich infantil em nós, produzindo um gozo de singular mal-estar, destes somente produzidos pela brincadeira na infância ou pelo sonho.

Švankmajer nos apresenta a maravilha do infantil, com sua atmosfera, por vezes formidável. Suas sombras e encantos advém da precariedade linguageira do sonho, carecendo invenção, fluxo, jogo de non sense com as palavras.

A partir desse livro, acusado muitas vezes, dentro do próprio campo psicanalítico, de incitar a agressividade e a recusa da realidade, Švankmajer traz no cerne de sua produção uma problemática a fazer eco com o que de mais original se produziu desde a psicanálise acerca do infantil, e daquilo que poderíamos considerar como fundamental no trabalho da criança, na sua apreensão do mundo como estruturado pela palavra. Ao menos, é nesse sentido que Lacan (1958-59/2002), em seu Seminário O desejo e sua interpretação, aponta para a grande contribuição de Alice, uma vez que ela nos mostra que o fundamento da entrada da criança no jogo significante, antes de se dar pela via do sentido opera pelo avesso do significante enquanto tal, em uma dimensão líquida que é propriamente o campo de um jogo com o non sense:

(...) devo dizer que, se tivesse que aconselhar como livro introdutório àquilo que deve ser um psiquiatra ou psicanalista de crianças, mais do que não importa qual dos livros de Piaget, eu lhes aconselharia ler As aventuras de Alice... Já que captaria efetivamente essa coisa sobre a qual tenho as melhores razões para pensar, levando em conta aquilo que se sabe de Lewis Caroll, que é isso que repousa sobre a profunda experiência do jogo de palavras da criança, e que, efetivamente, nos mostra o valor, a incidência, a dimensão do jogo de non sense como tal. (p. 185)

Dificil, também, não construir aqui neste contexto, uma intertextualidade com "O poeta e o fantasiar", de 1908, texto crucial de Freud (1908/2015) acerca da poesia e o fazer poético. Esse nos apresenta uma aproximação das construções poéticas, com as "imaginativas", do brincar infantil. "Toda criança brincando se comporta como um poeta, na medida em que ela cria seu próprio mundo, melhor dizendo, transpõe as coisas do seu mundo para uma nova ordem, que lhe agrada" (Freud, 1908/2015, p. 54). Nesse sentido, Freud vai nos dizer que a própria linguagem preservou essa original relação entre o brincar e a criação poética e, ainda, que 
(...) a irrealidade do mundo poético, se seguem importantes consequências para a técnica artistica, pois muitas coisas que não poderiam causar gozo como reais podem fazê-lo no jogo da fantasia e muitas moções que em si são desagradáveis podem se tornar para o ouvinte ou espectador do poeta fonte de prazer. (pp. 54-55)

Uma questão que também nos oferece uma perspectiva para esse mal-estar vivido com "júbilo singular", ao qual nos remetia Lacan (2004) acerca do texto de L. Carroll.

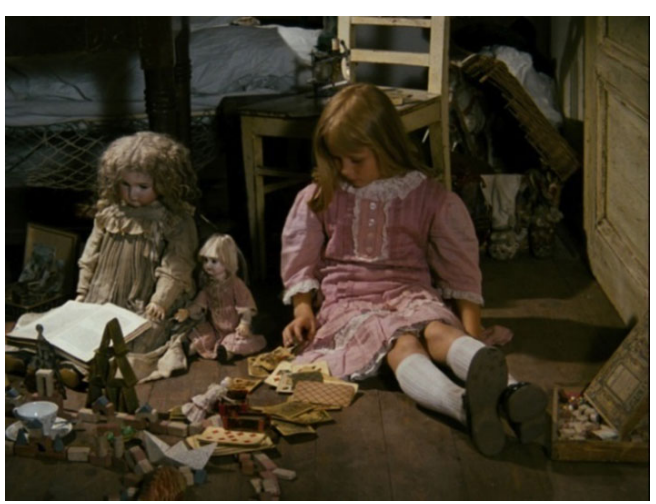

Figura 6

Nesse ambiente de sonho criado pelas imagens poéticas de Švankmajer, Alice é contada como o brincar de uma criança. Uma criança brincando de animar os objetos gastos da memória. Elida Tessler (2012) nos oferece uma bela imagem desse fator infantil na experiência do artista, em se fazer valer do retorno, da criação dessas memórias, da reativação dessas marcas, perseguidas pelos rastros perdidos de um infantil arcaico:

[...] tudo o que passo a escrever agora tem o cheiro da tinta têmpera. Vem de uma história que perpassa infâncias, e que diz respeito aos nossos desejos de imagem. Quem de nós já não criou paisagens, casas, barcos e personagens com um pincel embebido em têmpera ou guache? Tempero de memória, esta tinta a base d'água é a mesma com que queremos sempre colorir o que sobrou das garatujas de uma infância lavada com sabão de glicerina, preocupação de quem cuidava das nossas roupas quando do retorno da escola. (p. 129)

Dar cores a essas garatujas que resistem ao tempo, que insistem evocando esses arcaicos desejos de imagem que o olhar de Švankmajer tão bem soube saber fazer emergir. 


\section{LITERATURA, ARTE, CULTURA}

Esse país de maravilhas faz retornar o jogo incessante desses objetos, parciais, claudicantes, perdidos. Objetos, causa de um desejo utópico, que emerge nesse fundo não representável, ou propriamente infantil, da experiência humana. Ou, como nos diz Bloch (2005), em uma poética aproximação da utopia com o brincar das crianças:

O brincar transforma a seu gosto a própria criança, os seus amigos, todas as coisas à sua volta em algo estranhamente familiar: o chão do quarto de brincar torna-se uma selva cheia de feras ou um mar em que cada cadeira é um barco. Porém, quando o habitual se distancia demais ou custa a reassumir a feição antiga, irrompe a angústia. (p. 30)

Alice desperta, assim, angustiada! Desperta exatamente quando emerge esse excesso de realidade que nos tira o sono e o sonho. Os imperativos, também ilógicos, de um Outro excessivamente familiar, que insiste em julgar o infantil nesse tribunal em que a lei se mostra absoluta, e, cuja sentença para os que insistem em sonhar o sonho utópico, está sempre dada, de antemão: - Cortem-lhe a cabeça!

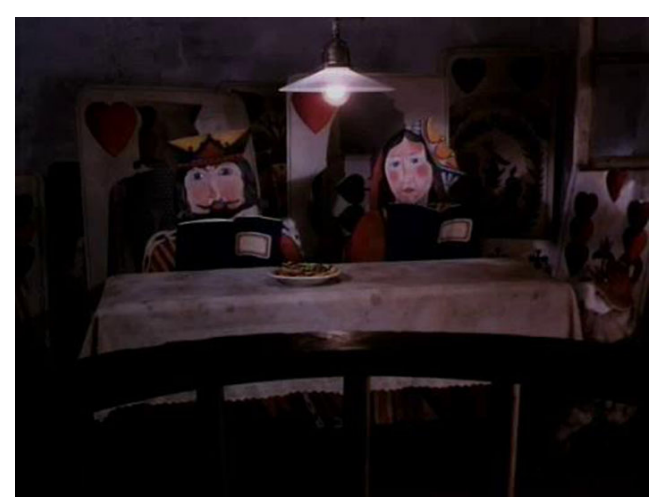

Figura 7

Povoados de ilhas, damos um fim a essa travessia, sabedores do retorno "moebiano" que aí se anuncia. Talvez despertados, também, pelo excesso angustiante dos imperativos da realidade do mundo. Mas algo insiste em nós! Algo que nos deixa boquiabertos com sua potência em produzir estranhamentos.

Incrível o que pode fazer um corte - ou um furo - , em um istmo, uma ilha que infinitamente se desdobra em outras ilhas, ou países. Seja como for constituem um universo de fantasia e sonho que nos aproxima dessa dimensão da utopia atravessada pela emocionante racionalidade do inconsciente, que a psicanálise engendra para dizer disso que resiste, insiste e repete; puro jogo da 
criança que elabora com os restos dos objetos de sua constituição uma utopia que tenta resguardar, como furo, como corte, a singularidade do desejo e da criação.

A criança que em seu brincar, como nos diz Ernst Bloch (2005), se movimenta em uma busca ávida, mas que também aprende a esperar-se pelo desejo. Uma criança que tudo agarra, que tudo joga fora, curiosa, não encontra jamais o objeto adequado. Uma criança que, em nome do brincar, destrói o que lhe é presenteado. "Assim, o que é novo se esvai, ainda não comparece" (p. 29). E, justamente por isso, procura uma viajem longa, rumo, talvez, à sua própria ilha de Utopia. "Aquilo que é importante continua sempre faltando. Portanto, o sonho não pára de se infiltrar nas lacunas" (p. 37).

Assim também são as imagens de Švankmajer que tão bem soube ler Alice. Não param, barrocamente, de infiltrar-se nas lacunas; não cessam de dirigir-se, seja por seu excesso ou perda (suas imagens-objetos estão sempre caíndo), a isso que insistentemente fracassa em se fazer imagem, mas que alimenta o sonho da utopia carroliana. Esse infantil que, desde a psicanálise, faz testemunho do inconsciente, com suas condensações metafóricas e 152 deslocamentos, metonímias de um desejo a se situar sempre mais além, qual uma ilha no horizonte, qual um sonho que se tenta fazer retornar pela fala, sempre fugidío. Uma utopia como um furo nas imagens impregnadas de uma realidade que quer sempre o absoluto de sua função realizante. Os vastos jogos de non sense desdobram um horizonte que descortina a possibilidade da criação de Outro tempo e linguagem, em nós e com Alice; uma resistência inventiva do infantil que insiste lá — onde o que de nós é mais humano — , e muitas vezes, quase não chega (a tempo).

\section{Referências}

Agamben, G. (2005). Infância e história: Destruição da experiência e origem da história. Belo Horizonte, MG: Editora UFMG.

Bloch, E. (2005). O princípio esperança. (Vol. I). Rio de Janeiro, RJ: EdUERJ: Contraponto.

Carroll, L. (1998). Alice no país das maravilhas. Porto Alegre, RS: L\&PM.

Corso, D. L., \& Corso, M. (2011). A psicanálise na terra do nunca: ensaios sobre a fantasia. Porto Alegre, RS: Penso. 


\section{LITERATURA, ARTE, CULTURA}

Dadoun, R. UTOPIA: a emocionante racionalidade do inconsciente. (Elemar do Amor Divino, trad. [uso interno à disciplina "A melodia das coisas", PPGPSIUFRGS, 2015/2]). Recuperado em 10 nov. 2017, de: <http://www.appoa.com.br/ uploads/arquivos/1171_utopia.pdf>.

Didi-Huberman, G. (2010). O que vemos, o que nos olha. São Paulo, SP: Editora 34. Elia, L. (2010). O conceito de sujeito. Rio de Janeiro, RJ: Jorge Zahar.

Freud, S. (1976a). Os chistes e sua relação com o inconsciente. In Edição Standard Brasileira das Obras Psicológicas Completas de Sigmund Freud (Vol. VIII). Rio de Janeiro: Imago. (Trabalho original publicado em 1905).

Freud, S. (1976b). O estranho. In Edição Standard Brasileira das Obras Psicológicas Completas de Sigmund Freud (Vol. XVII). Rio de Janeiro, RJ: Imago. (Trabalho original publicado em 1919).

Freud, S. (2015). O poeta e o fantasiar. In Arte, literatura e os artistas. (Ernani Chaves, trad.). Belo Horizonte, MG: Autêntica. (Trabalho original publicado em 1908). .

Jacoby, R. (2007). Imagem imperfeita: pensamento utópico para uma época antiutópica. Rio de Janeiro, RJ: Civilização Brasileira.

Lacan, J. (2002). O seminário. Livro 6. O desejo e sua interpretação. Lição 9, de 21 de janeiro de 1959. Publicação não comercial. Circulação interna da Associação Psicanalítica de Porto Alegre. (Trabalho original publicado em 1958-59).

Lacan, J. (2003). Lituraterra. In Outros Escritos. Rio de Janeiro, RJ: Jorge Zahar. (Trabalho original publicado em 1971).

Lacan, J. (2004). Homenagem a Lewis Carrol. In Miller, J. Ornicar?: 1. De Lacan a Lewis Carroll. Rio de Janeiro, RJ: Jorge Zahar.

Marin, L. (1989). La fiction poetique de l'utopie. Cinéma et Littérature (Valence. Centre de recherche et d'action culturelle). Utopies, 7, 13-20.

Morus, T. (2009). Utopia. São Paulo, SP: Editora WMF Martins Fontes.

Sarduy, S. (1979). Escrito sobre um corpo: por uma ética do desperdício. São Paulo, SP: Perspectiva.

Sousa, E. L. A. (2008). A imagem imperfeita. Revista da Associação Psicanalítica de Porto Alegre. 34 (1), 11-22.

Sousa, E. L. A. (2011). Por uma cultura da utopia. E-topia: Revista Electrónica de estudos sobre a Utopia, 12. Recuperado em 2 fev. 2017, de: <http://ler.letras.up.pt/ site/default.aspx?qry=id05id164\&sum $=$ sim $>$.

Sousa, E. L. A. (2014). Samuel Beckett - Breve gramática do inominável. In L. S. Pereira, A ficção na psicanálise: passagem pela Outra cena. Porto Alegre, RS: Instituto APPOA. 
Sousa, E. L. A., \& Endo, P. (2009). Sigmund Freud: ciência, arte e política. Porto Alegre, RS: LP\&M.

Tessler, E. S. (2012). Habitar o silêncio, esculpir o tempo. In T. M. G. Fonseca, B. L. Brites (Orgs.), Eu sou você. Porto Alegre, RS: Editora da UFRGS.

Zavaroni, D. de M. L. et al. (2007). A constituição do infantil na obra de Freud. Estudos de Psicologia, 12(1), 65-70 (Publicação - PPgPsi-UFRN Print version ISSN 1413-294X).

\section{Resumos}

(A country of wonders! The infantile of utopia)

In this essay, we have aimed at building a few connections between the psychoanalytical conception of the infantile and the utopian universe. Based on Jam Švankmajer's cinematographic version of Alice in Wonderland - which offers a perspective of Lewis Carroll's universe of Alice that comes close to Freud's concept of dreams and child's play - we tried to find connections between the infantile and utopia by relating Švankmajer's "Wonderland" to Morus' island of Utopia to show how the infantile allows to access utopian constructions by a cut or hole in the wordimages of the infantile, as a demand to create, through play, a coastline that gives us access to islands, territories that resist the literality of the instituted shapes of reality, such as utopia does.

Key words: Infantile, utopia, psychoanalysis, writing, play

(Un pays de merveilles! L'enfantile de l'utopia)

Dans cet essai, nous cherchons à tisser quelques liens entre l'infantile de la notion psychanalytique et l'univers des utopies. Sur la base de la version cinématographique d'Alice au pays des Merveilles de Jam Švankmajer - dans laquelle l'auteur nous offre une perspective de l'univers carrollien d'Alice semblable au rêve et au jeu d'enfants du point de vue freudien -, nous essayons d'approcher l'infantile et l'utopie en établissant un rapport entre "Le Pays de Merveilles», présenté par Švankmajer et l'île «Utopia» de Morus. Ainsi, nous visons à montrer comment l'infantile donne accès à des constructions utopiques grâce à une coupure ou à la percée d'un trou dans les mots-images de l'infantile, menée comme une exigence de la création, par le jeu, d'une côte qui offre accès à des îles, des territoires qui résistent à la littéralité des formes établies par la réalité, c'est-à-dire l'utopie.

Mots clés: Infantile, utopie, psychanalyse, écriture, jouer 


\section{LITERATURA, ARTE, CULTURA}

(¡Un país de maravillas! El infantil de la utopia)

En este ensayo, buscamos construir algunos lazos entre lo infantil, en la concepción psicoanalítica, y el universo de las utopías. A partir de la versión cinematográfica de Alicia en el país de las maravillas, de Jam Švankmajer; en donde el autor logra ofrecernos una perspectiva del universo carroliano de Alice, alrededor del sueño y del jugar de los niños en la concepción freudiana, buscamos aproximar lo infantil y la utopía, relacionando el "País de las maravillas", presentado por Jam Švankmajer, con la isla de Utopía, de Moro, con la intención de demostrar cómo lo infantil abre el acceso a las construcciones utópicas a partir de un corte o agujero en las palabras/imágenes de lo infantil, como exigencia de la creación, por el jugar, de un litoral que nos da acceso a islas, territorios que se resisten a la literalidad de las formas instituidas de la realidad, como utopía.

Palabras claves: Infantil, utopía, psicoanálisis, escritura, jugar

Citação/Citation: Medeiros, M. P., \& Sousa, E. L. A. (2020, mar.). Um país de maravilhas! O infantil da utopia. Revista Latinoamericana de Psicopatologia Fundamental, 23(1), 135-156. http://dx.doi.org/10.1590/1415-4714.2020v23n1p135.9.

Editora/Editor: Profa. Dra. Sonia Leite

Submetido/Submitted: 14.4.2019/4.14.2019 Aceito/Accepted: 18.7.2019/ 7.18.2019

Copyright: (C) 2009 Associação Universitária de Pesquisa em Psicopatologia Fundamental/ University Association for Research in Fundamental Psychopathology. Este é um artigo de livre acesso, que permite uso irrestrito, distribuição e reprodução em qualquer meio, desde que o autor e a fonte sejam citados / This is an open-access article, which permits unrestricted use, distribution, and reproduction in any medium, provided the original authors and sources are credited.

Financiamento/Funding: Este trabalho tem apoio da Coordenação de Aperfeiçoamento de Pessoal de Nível Superior - Capes / This work is supported by Coordenação de Aperfeiçoamento de Pessoal de Nível Superior - Capes.

Conflito de interesses/Conflict of interest: Os autores declaram que não há conflito de interesses / The authors have no conflict of interest to declare. 


\section{Marcos Pippi de Medeiros}

Psicanalista; Professor do curso de Psicologia da Universidade Franciscana - UFN (Santa Maria, RS, Brasil); Graduado em Psicologia Pela Universidade Regional do Noroeste do Estado do Rio Grande do Sul - Unijuí (Ijuí, RS, Brasil); Mestre em Psicologia Clínica pela Pontifícia Universidade Católica de São Paulo - PUC-SP (São Paulo, SP, Brasil); Doutor em Psicologia Social e Institucional pela Universidade Federal do Rio Grande do Sul - UFRGS (Porto Alegre, RS, Brasil); Integrante do LAPPAP - Laboratório de Pesquisa em Psicanálise, Arte e Política.

Rua Ernesto Lopes, 20

97110-280 Santa Maria, RS, Br. marcospippi.m@gmail.com

https://orcid.org/0000-0001-8371-0638

\section{Edson Luiz André de Sousa}

Professor do Programa de Pós-Graduação em Psicanálise: clínica e cultura da Universidade Federal do Rio Grande do Sul - UFRGS (Porto Alegre, RS, Brasil); Professor titular do Departamento de Psicanálise e Psicopatologia do Instituto de Psicologia - Universidade Federal do Rio Grande do Sul - UFRGS (Porto Alegre, RS, Brasil); Doutor em Psicanálise e Psicopatologia pela Universidade de Paris VII; Pesquisador do CNPq; Coordena, junto com Maria Cristina Poli, o LAPPAP (Laboratório de Pesquisa em Psicanálise, Arte e Política); Membro da Society of Utopian Studies; Analista membro da Associação Psicanalítica de Porto Alegre (Porto Alegre, RS, Brasil); Professor visitante na Deakin Universtiy (Melbourne, 2006); Professor visitante no Instituto de Estudos Críticos (Cidade do México, 2007); Pesquisador colaborador do grupo Pandora - Université de Paris VII (Paris, França). Autor dos livros Freud: ciência, arte e política junto com Paulo Endo (Porto Alegre: LPM, 2009), Uma invenção da Utopia (São Paulo: Lumme Editor, 2007), Freud (São Paulo: Editora Abril, 2005).

Rua Fernandes Vieira, 474/32

90035-090 Porto Alegre, RS, Br.

edsonlasousa@uol.com.br

https://orcid.org/0000-0002-1634-230X

This is an open-access article, which permits unrestricted use, distribution, and reproduction in any medium for non-commercial purposes provided the original authors and sources are credited. 